\title{
Synthesis of Amino Magnetic Titano-Silicate and Its Role for Uranium Adsorption
}

\section{Gado MA, Abdou AA and Zaki SA*}

Nuclear Materials Authority, 530 P.O Box Maadi, Cairo, Egypt

*Corresponding author: Zaki SA, Nuclear Materials Authority, 530 P.O Box Maadi, Cairo, Egypt, Tel: +20227572499; E-mail: salah.afify@yahoo.com

Received: November 20, 2017; Accepted: December 05, 2017; Published: December 11, 2017

Copyright: ( 2017 Gado MA, et al. This is an open-access article distributed under the terms of the Creative Commons Attribution License, which permits unrestricted use, distribution, and reproduction in any medium, provided the original author and source are credited.

\begin{abstract}
Amino magnetic titano-silicate was prepared by two different methods in the presence of dispersed fine magnetite particles the obtained composites named (AMTS and IMTS) were used as an adsorbent to remove U(VI) ions from aqueous solutions and rock samples by a batch method. Various conditions were evaluated, including solution pH, initial uranium concentration, adsorbent dosage, and contact time. The adsorption kinetics and equilibrium isotherms of U(VI) by the AMTS and IMTS composite were studied using the pseudo-first-order and pseudo-second-order kinetic models as well as Langmuir and Freundlich isotherm models. The kinetic data followed the pseudo-secondorder equation; the isotherm data were described by the Langmuir isotherm model and the maximum adsorption capacity $\left(Q_{\max }\right)$ was obtained at 142.2 and $133.33 \mathrm{mg} / \mathrm{g}$ for AMTS and IMTS, respectively.
\end{abstract}

Keywords: Amino magnetic; Titano-silicate; Impregnation; Adsorption; Uranium

\section{Introduction}

Resins are the most well-known ion exchangers, though zeolitic materials can be an excellent alternative to the most conventional sorbents since they possess high surface area and ion exchange capacity and are predominantly innocuous materials. One may cite, for instance, mixed octahedral-pentahedral-tetrahedral (OPT) microporous siliceous frameworks like Engelhard titanosilicate material number 4 (ETS-4) and Engelhard titanosilicate material number 10 (ETS-10). OPT materials offer excellent opportunities for ion exchange applications [1].

Titano-silicates represent a new and rapidly expanding class of porous materials with important applications in catalysis, gas separation [2], ion-exchange [3] etc. As an effort to reduce the heavy metal and radionuclide levels in water (waste water, drinking water or water for the agriculture) to the maximum permissible concentration, selective removal (by ionic exchange, adsorption, precipitation and membrane separation) is currently employed [4].

The presence of radionuclides in wastes is a major environmental concern. Removing radioactive ions from waste water is an important issue in liquid waste treatment because these ions are hazardous with respect to the environment and human health give both their high toxicity even at low concentrations and their half life time (long half live times). The occurrence of these pollutants in water is directly related to industrial activities such as mining, nuclear power generation plants, nuclear weapon production, and various laboratory activities [5]. The system here suggested has been preferred as uranium is the most abundant constituent of nuclear wastes.

In order to protect the environment, animals and human settlements from sources of radionuclides, efficient decontaminating processes, techniques and materials must be developed. This paper focuses on developing titanosilicate derivatives for this purpose.
A wide range of methods have been proposed and applied to remediate radioactive pollution in aqueous solutions, such as drinking, sea, mine waters and liquid radioactive wastes (LRW) [6-8]. These include bioremediation, solvent extraction, precipitation, evaporation, adsorption, ion exchange and membrane techniques and combinations thereof. Due to the specific properties related to the framework structure and high ion exchange capacity (ca. 6.0 meq.g ${ }^{-1}$, hydrous basis), ETS-4 titano-silicate is especially recommended for safe storage and removal of radioactive elements from nuclear waste. The ETS-4, [9] is a member of the Engelhard Titanium Silicate family having a uniform pore size of ca. $4 \AA$. this material is structurally very interesting and is related to mineral zorite, although not its synthetic counterpart.

Ion exchange and adsorption are the most commonly used methods for LRW chemical processing [10,11]. Obviously, these methods do not have ideal removal selectivity. Sorption materials sensitive enough to separate individual nuclide ions have not yet been invented. Nevertheless, sorption materials make it possible to decrease LRW levels by retaining the radionuclides in a solid form, while the deactivated water can be reused or safely released to the environment.

Despite its smaller pore radius of $3.7 \AA$, the ability of ETS- 4 to sorb large cations like, $\mathrm{UO}_{2}{ }^{2+},{ }^{241} \mathrm{Am}^{3+}$ and ${ }^{236,239,240} \mathrm{Pu}^{3+}$ were estimated by Al-Attar et al., from 2000-2003 [12-15]. The selectivity of ETS-4 to $\mathrm{UO} 22+$ was compared with CTS, AM-4 and ETS-10 titanosilicate materials using the batch $\mathrm{Kd}$. The influence of batch factor, contact time, sorbate concentration and structural aspects on the ion exchange capacity of the studied materials was discussed by Al-Attar and Dyer [15]. A much lower Kd was reported for ETS-4 than for ETS-10 in the irst study by Al-Attar [15]. For sorption of $\mathrm{U}$ on TiSi materials, both surface precipitation and ion exchange mechanisms were suggested [14]. The present paper is focused on the preparation of new amino derivatives of titano-silicate with simple and low-cost method with comparing it with other amino titano-silicate prepared with different methods and adsorption of uranium ions from synthetic solution and rock samples. 
Page 2 of 9

\section{Experimental}

\section{Materials and methods}

All reagents were of analytical grade (Aldrich) and were used without further purification. All of the solutions were prepared with fresh double distilled water. Tetraethylorthosilicate $\left(\mathrm{Si}\left(\mathrm{OC}_{2} \mathrm{H}_{5}\right)_{4}\right.$, TEOS, 98\%), titanium isopropoxide $\left(\mathrm{Ti}\left(\mathrm{OC}_{3} \mathrm{H}_{7}\right)_{4}\right.$, TIP; 99\%), 3Aminopropyltriethoxysilane $\left(\mathrm{H}_{2} \mathrm{~N}\left(\mathrm{CH}_{2}\right)_{3} \mathrm{Si}\left(\mathrm{OC}_{2} \mathrm{H}_{5}\right)_{3}\right.$, APTES, 99\%) were purchased from Sigma-Aldrich. Sodium hydroxide $(\mathrm{NaOH}$; 99.9\%), and nitric acid $\left(\mathrm{HNO}_{3}, 63 \mathrm{wt} \%\right)$, A uranium stock solution containing $1000 \mathrm{mg} / \mathrm{L}$ of $\mathrm{U}(\mathrm{VI})$ was prepared by dissolving $1.782 \mathrm{~g}$ of uranyl acetate in $1 \%$ nitric acid and diluting to $1000 \mathrm{ml}$ using the double distilled water.

The U(VI) measurement was estimated spectrophotometrically using Arsenazo III method [16] by the PC scanning spectrophotometer UV/VIS double beam of the type Labomed, Inc. (USA).

Nanomagnetite was prepared following the modified Massart method [17]. $100 \mathrm{ml}(0.2 \mathrm{M})$ of $\mathrm{Fe}^{3+}$ solutions was added, with stirring, to freshly prepared $100 \mathrm{ml}(0.1 \mathrm{M})$ of $\mathrm{Fe}^{2+}$ solutions. Then, $100 \mathrm{ml}$ of ammonia solution $(30 \%)$ was suddenly poured into the previously prepared $\mathrm{Fe}^{3+} / \mathrm{Fe}^{2+}$ solutions with vigorous stirring. A black precipitate was formed and was allowed to crystallize for $30 \mathrm{~min}$ with stirring. The precipitate was washed with deoxygenated water (water was boiled to repeal any gases and then bubbled with nitrogen gas) under magnetic decantation until $\mathrm{pH}$ of suspension became below 7.5. The precipitate was dried at room temperature to give a black powder.

\section{Preparation of ETS-4 type}

An alkaline solution was made by dissolving $33.16 \mathrm{gm}$ of metasilicate and $2 \mathrm{gm} \mathrm{NaOH}$ and $3 \mathrm{gm} \mathrm{KCl}$ into $25.4 \mathrm{gm} \mathrm{H}_{2} \mathrm{O}$ and $31.88 \mathrm{gm} \mathrm{TiCl}_{3}\left(15 \% \mathrm{~m} / \mathrm{m} \mathrm{TiCl}_{3}\right.$ and $\left.10 \% \mathrm{~m} / \mathrm{m} \mathrm{HCl}\right)$ were added to this solution and stirred thoroughly. this gel with a molar composition 0.4 $\mathrm{Na}_{2} \mathrm{O}: 1.7 \mathrm{SiO}_{2}: 1.0 \quad \mathrm{TiO}_{2}: 30 \mathrm{H}_{2} \mathrm{O}$ was transferred to a Teflon-lined autoclave and treated at $230^{\circ} \mathrm{C}$ for 17 hours, the product was filtered off, washed at room temperature, with distilled water and dried at $70^{\circ} \mathrm{C}$ overnight, the final product being an off-white microcrystalline powder $\left[(\mathrm{Na}, \mathrm{K})_{2} \mathrm{TiSi}_{2.5} \mathrm{O}_{13} \cdot 4 \mathrm{H}_{2} \mathrm{O}\right][18,19]$.

\section{Preparation of the Amino-Modified Magnetic Titano-Silicate (AMTS)}

The used titano-silicates were synthesized by the hydrothermal method. To this end, in a beaker, $3.53 \mathrm{ml}$ of tetraethyl orthosilicate as well as $3.44 \mathrm{ml}$ titanium isopropoxide was added to $50 \mathrm{ml}$ of a solution containing $12.64 \mathrm{~g}$ sodium hydroxide, $1.77 \mathrm{~g} \mathrm{Fe}_{3} \mathrm{O}_{4}$ and stirred magnetically for 1 hour. The obtained white solution was heated at $443^{\circ} \mathrm{K}$ for four days using a $100 \mathrm{ml}$ Teflon-lined stainless steel autoclave. The resulting precipitate was separated from the reaction medium by centrifugation, washed with deionized water several times and dried overnight in a vacuum oven at $343^{\circ} \mathrm{K}$. In the second step, a weighed amount of the obtained product was dissolved in distilled water and ultrasonicated (Bandelin SONOPULS HD2200, Germany) for about an hour. Subsequently, 3-Aminopropyltriethoxysilane (APTES) with different $\%$ weight (0 to $40 \%$ ) was added and stirred for 20 hours. Then the derived precipitate was separated in a centrifuge and dried overnight in a vacuum oven at $323^{\circ} \mathrm{K}$. The product obtained was denoted as AMTS.

\section{Preparation of the Amino-Modified Magnetic Titano-Silicate with impregnation (AMTS)}

The preparation occurs using impregnation of magnetic titanosilicate in ethylenediamine, $1.5 \mathrm{~g}$ of magnetic titano-silicates was mixed with $30 \mathrm{ml}$ ethylenediamine solution in a $100 \mathrm{ml}$ reaction flask. The mixture was refluxed at $120^{\circ} \mathrm{C}$ for 40 hours. The reaction mixture was poured into cold water and the solid was filtered and washed with $0.1 \mathrm{M} \mathrm{NaCl}$ solution until the filtrate was free from the amine. The remained $\mathrm{NaCl}$ was washed with water and methanol. The functionalized adsorbents were dried at $70^{\circ} \mathrm{C}$ and designated as IMTS.

\section{Adsorption experiments}

Adsorption experiments under controlled $\mathrm{pH}$ were carried out by adding portions of $0.1 \mathrm{~g}$ resin in a series of flasks, each one containing $20 \mathrm{ml}$ solution of $(250 \mathrm{mg} / \mathrm{L}) \mathrm{U}(\mathrm{VI})$ ions solution. The $\mathrm{pH}$ was adapted to the range of 1-6 using hydrochloric acid or sodium hydroxide solutions. The flasks were shaken on a shaking water bath model 1083 (Labortechnik GmbH, Germany) at $300 \mathrm{rpm}$ for 2 hours at $25^{\circ} \mathrm{C}$. After equilibration, the residual concentration of the metal ion was determined.

To conduct the time effect, $0.1 \mathrm{~g}$ of AMTS or IMTS was put in a series of flasks containing $20 \mathrm{ml}$ of $\mathrm{U}(\mathrm{VI})$ ions solution $(250 \mathrm{mg} / \mathrm{L})$ at $\mathrm{pH}$ 5. The flasks were shaken on a shaking water bath for the required time period. The effect of initial concentration of $\mathrm{U}(\mathrm{VI})$ ion was carried out at definite concentrations $(250-1000 \mathrm{mg} / \mathrm{L})$ and $\mathrm{pH}$ 5. The contents of the flasks were equilibrated on a shaking water bath while keeping the temperature at 25,40 and $60^{\circ} \mathrm{C}$. After adsorption, the residual $\mathrm{U}(\mathrm{VI})$ concentration of the metal ion was determined.

The effect of the solid/liquid ratio on the adsorption efficiency of the studied resins was achieved by varying the amount of beads from 0.01 to $0.3 \mathrm{~g}$ in the adsorption medium $(20 \mathrm{ml}$ containing $250 \mathrm{mg} / \mathrm{L} \mathrm{U}(\mathrm{VI}))$, while keeping other parameters $(\mathrm{pH}$, contact time, and temperature) constant according to their values obtained from the previous experiments.

\section{Results and Discussion}

\section{Characterization of the adsorbent}

FT-IR results: The FT- IR spectra of AMTS and IMTS are shown in Figure 1, where the functional groups in the both AMTS and IMTS were identified by the comparison of FT-IR data of them. The FT-IR spectrum of the non-functionalized sample showed a broad band at $3,200-3,500 \mathrm{~cm}^{-1}$ (indicating $\mathrm{O}-\mathrm{H}$ stretch vibration), a number of absorption peaks at 994, 926, 867 and $728 \mathrm{~cm}^{-1}$ (corresponding to the $\mathrm{Si}-\mathrm{O}, \mathrm{Si}-\mathrm{O}-\mathrm{Ti}, \mathrm{Ti}-\mathrm{O}-\mathrm{Ti}$ and $\mathrm{Ti}-\mathrm{O}$ stretch vibration, respectively), and a peak at $451 \mathrm{~cm}^{-1}$ (ascribed to the Si-O-Si bending) [20-23].

The FT-IR spectrum of the AMTS showed a new peak at 2,910 $\mathrm{cm}^{-1}$ (indicating stretch vibration of $\mathrm{C}-\mathrm{H}$ bond of functionalized titanosilicate) and two new peaks at 1,639 and $1,382 \mathrm{~cm}^{-1}$ (relating to bending of an $\mathrm{NH} 2$ functional group and $\mathrm{HCH}$ bond, respectively). Furthermore, the new peak at $3,370 \mathrm{~cm}^{-1}$ overlapping the broad band at $3,200-3,500 \mathrm{~cm}^{-1}$ (corresponding to $\mathrm{O}-\mathrm{H}$ stretch vibration, as mentioned above). On the other hand, the peak at $750-780 \mathrm{~cm}^{-1}$ (indicating the $\mathrm{Si}-\mathrm{OH}$ vibration) that was observed in the AMTS disappeared in the IMTS. These groups are very sensitive to functionalization, since this process may occur via the condensation of $\mathrm{Si}-\mathrm{OH}$ or Ti-OH groups, hydrolyzed together with the alkoxide 
molecules [24]. while in IMTS the bands at 3450 and $1620 \mathrm{~cm}^{-1}$ are due to $\mathrm{N}-\mathrm{H}$ bonds, most of the characteristic bands of the titanosilicates logically remained after impregnation, but with lower intensity, because, probably, the presence of functional groups attached to the matrix, the band at $1000-1020 \mathrm{~cm}^{-1}$ is assigned to the asymmetric Si-O-Si vibration, and the bands at $915-930 \mathrm{~cm}^{-1}$ are ascribed to Si-O-Ti bonds. Thus FT-IR results suggest that AMTS and IMTS were successfully prepared.

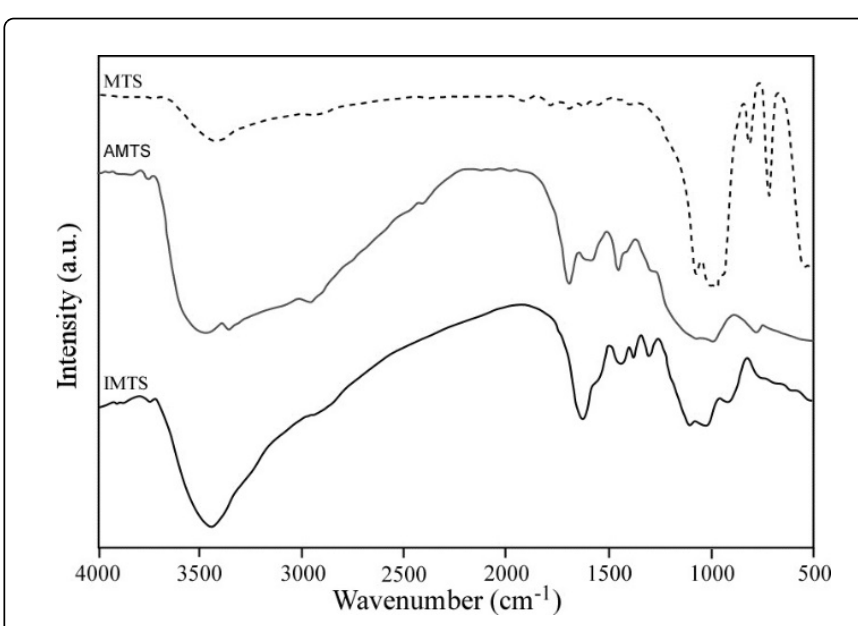

Figure 1: Infrared spectra of freshly prepared titano-silicate and modified one.

\section{Thermal stability studies}

Thermal analysis of the AMTS and IMTS were performed to establish their thermal stability and decomposition pathways. Mass losses observed during the TG/DSC analysis under air confirm a high amount of residual organic groups in the composites, (Figure 2).

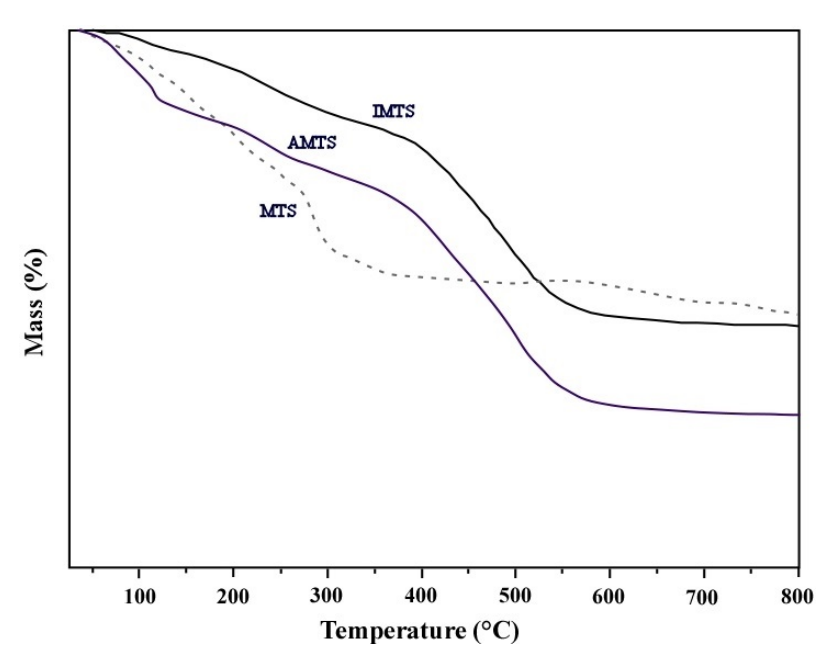

Figure 2: Thermo gravimetric analysis of prepared adsorbent.

It shows continuous water loss as a function of temperature in the range of 30 to $300^{\circ} \mathrm{C}$. The initial weight loss below $100^{\circ} \mathrm{C}$ could be attributed to the loss of its loosely bound moisture. The peak centered at about $216^{\circ} \mathrm{C}$ could be ascribed to the desorption of structural water. The profile becomes completely flat at around $300^{\circ} \mathrm{C}$, indicating that titano-silicate had lost all of its moisture. The second mass loss $\left(350-600^{\circ} \mathrm{C}\right)$ was ascribed to two factors: pyrolysis of organic groups, specifically ethylene di amine groups anchored onto the xerogels, and surface dehydroxylation, such as conversion of the surface silanol groups to siloxanes, which is typical of matrices prepared via sol-gel methodology.

\section{Chemical stability}

The chemical stability of AMTS and IMTS in acid and alkaline media was tested by shaking a $0.5 \mathrm{~g}$ portion of the resins in turn with $100 \mathrm{ml}$ of $1 \mathrm{M} \mathrm{HCl}$ and $1 \mathrm{M} \mathrm{NaOH}$ for 24 hours. The resins were then filtered off and washed with water. The adsorption capacities after the treatments were reduced by only $5-7 \%$, which were denoted as desirable stability of the resin. No obvious leakage of resins and change of resins were observed in the experimental process.

\section{Optimization of $U$ adsorption process}

To optimize the $\mathrm{U}(\mathrm{VI})$ adsorption several effective parameters were process studied; $\mathrm{pH}$, the amount of adsorbent, the contact time, temperature and the initial $\mathrm{U}(\mathrm{VI})$ concentration.

\section{Effect of $\mathbf{p H}$}

Uptake experiments under controlled $\mathrm{pH}$ were carried out by placing $0.1 \mathrm{~g}$ of MATS and IMTS in a series of flasks containing uranyl ions solution $250 \mathrm{ppm}$ for a $\mathrm{pH}$ range from 1 to 6 at $25^{\circ} \mathrm{C}$, respectively. The desired $\mathrm{pH}$ was adjusted using $\mathrm{HCl}$ and $\mathrm{NaOH}$. After the equilibration, the supernatant of each flask was obtained and the residual metal ion concentration was determined as shown above. It is well known that the initial $\mathrm{pH}$ value of the solution is a critical parameter that can affect the composite performance and ion uptake capability.

The $\mathrm{pH}$ has two kinds of influence on metal sorption an effect on the solubility and speciation of metal ions in solution, and on the overall charge of the sorbent. For selective adsorption, besides the use of a specific ligand modified sorbent, selectivity could be achieved by adjusting the $\mathrm{pH}$ of the medium to different values [25]. The $\mathrm{pH}$ dependence of adsorption values of $\mathrm{UO}_{2}{ }^{2+}$ was represented in Figure 3 it is obvious that the adsorption of $\mathrm{UO}_{2}{ }^{2+}$ onto AMTS and IMTS is $\mathrm{pH}$ dependent.

The results show that uranium adsorption by the composites is low at $\mathrm{pH} 1.0$, but increased with increasing $\mathrm{pH}$ and then reached the maximum at $\mathrm{pH}$ 5.0. Many authors reported various species of uranium at different $\mathrm{pH}$ values, [26,27] among these species, $\mathrm{UO}_{2}{ }^{2+}$, $\mathrm{UO}_{2}(\mathrm{OH})^{+}, \quad \mathrm{UO}_{2}(\mathrm{OH})_{2}(\mathrm{aq}), \quad \mathrm{UO}_{2}(\mathrm{OH})^{3-}, \quad\left(\mathrm{UO}_{2}\right)_{2}(\mathrm{OH})_{2}{ }^{2+}$, $\left(\mathrm{UO}_{2}\right)_{3}(\mathrm{OH})_{5}{ }^{+},\left(\mathrm{UO}_{2}\right)_{3}(\mathrm{OH})_{7}^{-},\left(\mathrm{UO}_{2}\right)_{4}(\mathrm{OH})_{7}{ }^{+}$, were detected. At $\mathrm{pH} \leq$ $5, \mathrm{UO}_{2}{ }^{2+}$ and $\mathrm{UO}_{2}(\mathrm{OH})^{+}$predominate and are responsible for uranium uptake by composites [28].

Different researchers indicated complex formation between $\mathrm{UO}_{2}{ }^{2+}$ and or $\mathrm{UO}_{2}(\mathrm{OH})^{+}$with different functional groups $[29,30]$. 


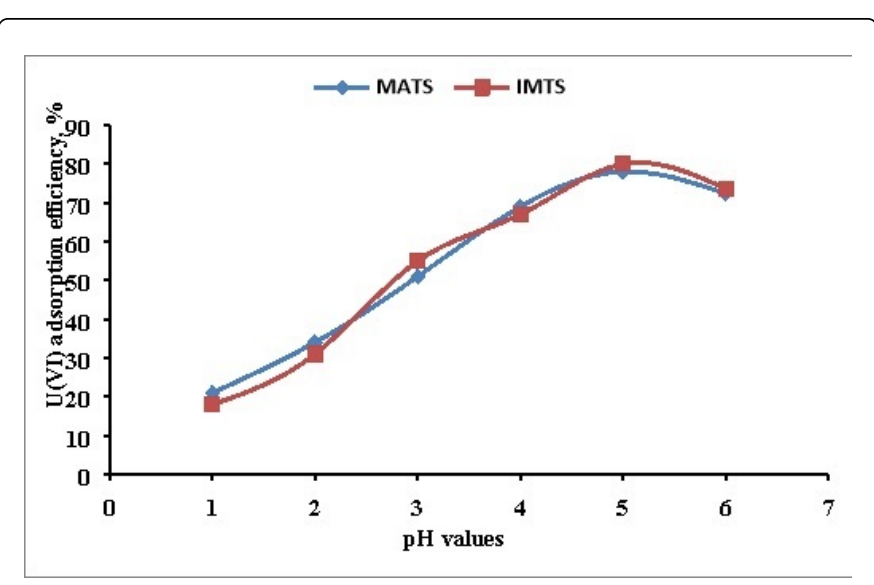

Figure 3: Effect of $\mathrm{pH}$ on Uranium adsorption.

\section{Effect of sorbent weight}

The effect of weight on the sorption of uranium from aqueous solutions on the AMTS and IMTS have examined in terms of changing the solution/solid ratio. This was performed by keeping uranium concentration constant at $250 \mathrm{mg} / \mathrm{L}$, and changing the weight of the sorbent in the range from 0.01 to $0.3 \mathrm{~g}$, as shown in Figure 4, when the adsorbent dosage is higher than $0.1 \mathrm{~g}$, the adsorption capacity of $\mathrm{U}(\mathrm{VI})$ on AMTS and IMTS is not significantly altered due to the increase of the dose with the same constant concentration of $\mathrm{U}(\mathrm{VI})$ on the medium. So, $0.1 \mathrm{~g}$ of AMTS and IMTS was chosen for the subsequent experiments.

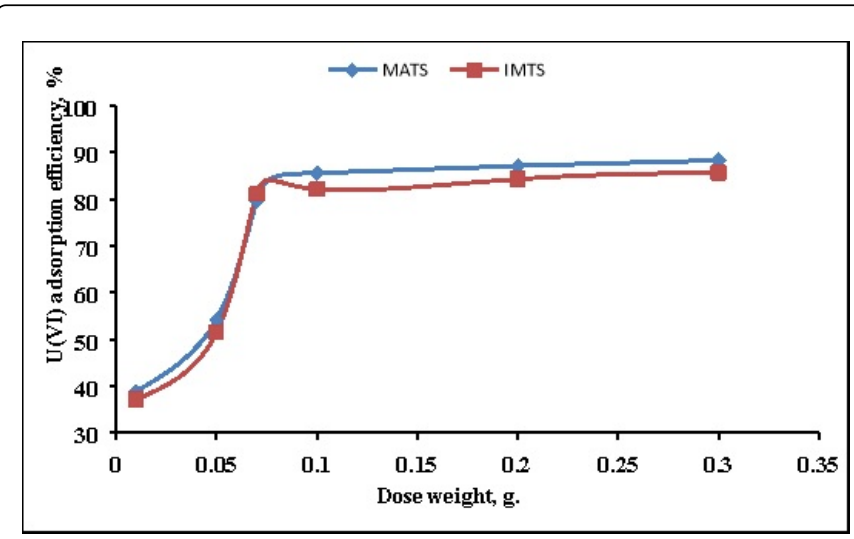

Figure 4: Effect of adsorbent dosage on Uranium adsorption.

\section{Effect of contact time and adsorption kinetics}

Sorption of U(VI) on both AMTS and IMTS resins were investigated as a function of contact time and the data obtained were shown in Figure 5. Uranium sorption increased as the contact time increased and reached its maximum sorption capacities at 45 and 30 min on AMTS and IMTS, respectively. To verify the order of the adsorption process pseudo-first-order kinetics and pseudo-secondorder kinetics models [31,32] were tested according to the following equations:

Pseudo first order:

$$
\log (q e-q t)=\log q e-\frac{k 1}{2.303} t
$$

Where qe $(\mathrm{mg} / \mathrm{g})$ and $\mathrm{qt}(\mathrm{mg} / \mathrm{g})$ are the amounts of adsorbate adsorbed at equilibrium and at contact time $\mathrm{t}(\mathrm{min})$, respectively, and $\mathrm{k}_{1}\left(\mathrm{~min}^{-1}\right)$ is the pseudo first-order rate constant. The values of $\mathrm{q}_{\mathrm{e}}$ and $\mathrm{k}_{1}$ for the pseudo-first-order kinetic model were determined from the intercept and the slope of the plot of $\log \left(\mathrm{q}_{\mathrm{e}}-\mathrm{q}_{\mathrm{t}}\right)$ vs. $t$ as shown in Figure 6 , respectively. The $k_{1}$ values, correlation coefficient values, and $q_{e}$ values (experimental and calculated) were summarized in Table 1.

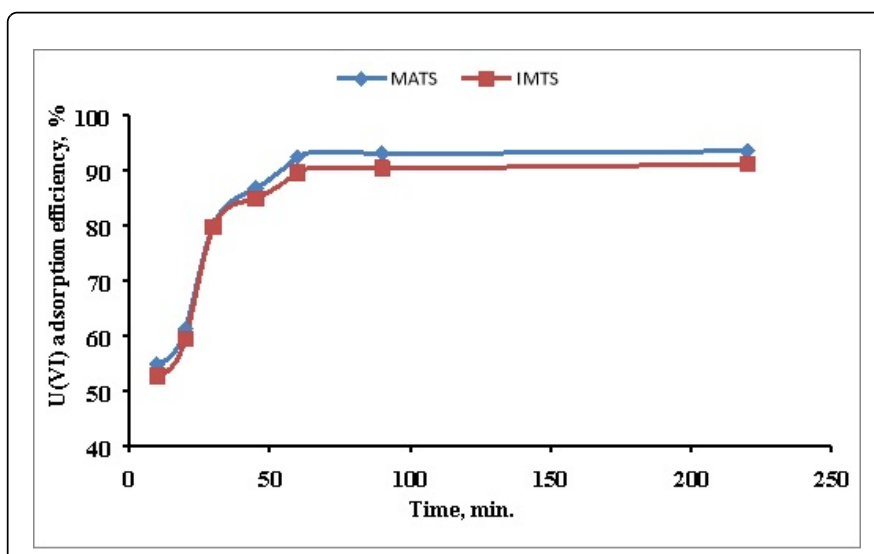

Figure 5: Effect of time on uranium adsorption.

The correlation coefficients, $\mathrm{R}^{2}$ values for the pseudo-first-order model changed in the range of 0.9643-0.9594 for AMTS and IMTS adsorption. Besides, the experimental qe values did not agree with the calculated values, $\mathrm{q}_{\mathrm{e}}$, cal obtained from the linear plots. It suggests that the adsorption of $\mathrm{U}(\mathrm{VI})$ did not follow the pseudo-first-order kinetic model.

\begin{tabular}{|l|l|l|l|l|l|l|l|}
\hline \multirow{2}{*}{ Resin } & \multirow{2}{*}{$\begin{array}{l}\text { Experimental } \\
\mathbf{q}_{\mathrm{e}}(\mathbf{m g} \mathbf{g})\end{array}$} & \multicolumn{4}{|l|}{ Pseudo-first-order kinetics } & \multicolumn{4}{l|}{ Pseudo-second-order kinetics } \\
\cline { 3 - 9 } & $\mathbf{q}_{\mathrm{e}}$ & $\mathbf{k}_{\mathbf{1}}\left(\mathbf{m i n}^{-1}\right)$ & $\mathbf{R}^{2}$ & $\mathbf{q}_{\mathrm{e}}$ & $\mathbf{k}_{2}\left(\mathbf{m i n}^{-1}\right)$ & $\mathbf{R}^{2}$ \\
\hline MATS & 46.75 & 42.6 & 0.0622 & 0.9643 & 48.544 & 0.0031 & 0.9983 \\
\hline MITS & 45.55 & 33.27 & 0.0541 & 0.9594 & 47.39 & 0.0032 & 0.9984 \\
\hline
\end{tabular}

Table 1: Kinetic data for adsorption of U(VI) on AMTS and IMTS composites. 
Page 5 of 9

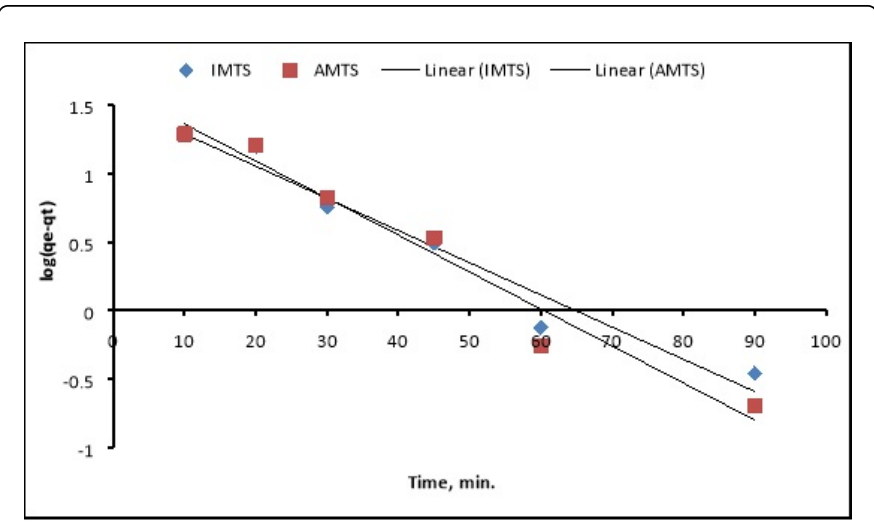

Figure 6: The pseudo-first-order kinetics model.

The pseudo-second order kinetic model can be represented in the following form [32]:

Pseudo-second order:

$$
\frac{t}{q t}=\frac{1}{k 2 q_{e}^{2}}+\frac{1}{q_{e}} t
$$

Where $\mathrm{k}^{2}(\mathrm{~g} /(\mathrm{mg} \mathrm{min}))$ is the rate constant of pseudo-second order adsorption. The $\mathrm{k}^{2}$ and $\mathrm{q}_{\mathrm{e}}$ values determined from the slope and intercepts of the plot of $t / q t$ vs. $t$ as shown in Figure 7 were presented in Table 1 along with the corresponding correlation coefficients. The correlation coefficients $\left(\mathrm{R}^{2}\right)$ values for the pseudo-second-order kinetic model were 0.9983 and 0.9984 for AMTS and IMTS respectively, indicating the applicability of the pseudo second-order kinetic model to describe the adsorption process of $\mathrm{U}(\mathrm{VI})$ on the AMTS and IMTS composites. The calculated qe value according to the pseudo-secondorder model agreed well with the experimental data. Therefore, the adsorption of $\mathrm{U}(\mathrm{VI})$ was better described by the pseudo second-order kinetic model rather than the pseudo-first order kinetic model.

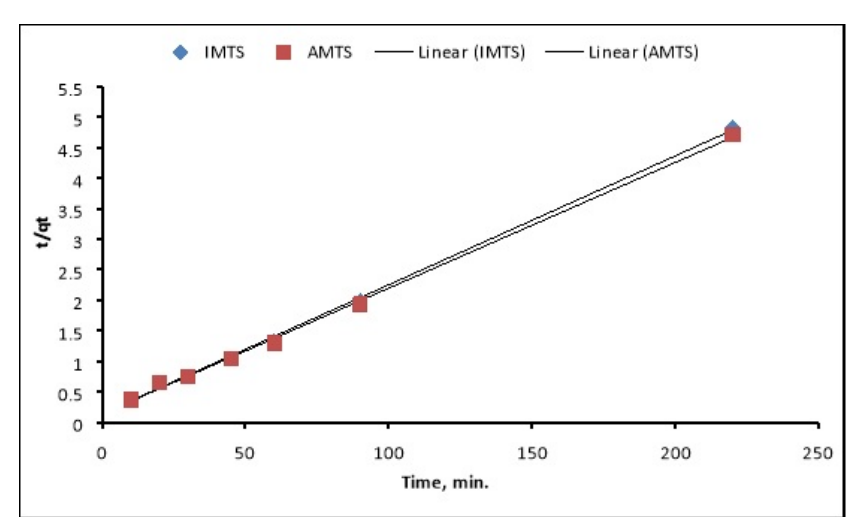

Figure 7: The pseudo-second-order kinetics model.

\section{Effect of initial U(VI) concentration on adsorption isotherms}

The effect of initial uranium concentration has been studied at three fixed temperatures 25,40 and $60^{\circ} \mathrm{C}$ and uranium concentration range between 100 and $1000 \mathrm{mg} / \mathrm{L}$. while the other parameters were kept constant. The adsorption isotherms including Langmuir and Freundlich isotherms $[33,34]$ were applied to evaluate the adsorption equilibrium data. For this purpose, $20 \mathrm{ml}$ of uranium solution with concentrations of 100 to $1000 \mathrm{mg} / \mathrm{L}$ were prepared at room temperature and adsorption of uranium was calculated by Equation 3 at $\mathrm{pH} 5$, using $0.1 \mathrm{~g}$ adsorbent and contact time of $45 \mathrm{~min}$. The linear form of the Langmuir isotherm is shown in Equation 4:

$$
\begin{gathered}
q=\frac{C_{i}-C_{f}}{M} x V \\
\frac{\mathrm{C}_{\mathrm{e}}}{\mathrm{q}_{\mathrm{e}}}=\frac{1}{\mathrm{~b} \mathrm{\textrm {q } _ { \mathrm { e } }}}+\frac{\mathrm{C}_{\mathrm{e}}}{\mathrm{q}_{\mathrm{e}}}
\end{gathered}
$$

Where qe is the amount of metal ion adsorbed by the adsorbent $(\mathrm{mg} / \mathrm{g})$, Ce is ion concentration at equilibrium $(\mathrm{mg} / \mathrm{L})$, qo is maximum adsorption capacity $(\mathrm{mg} / \mathrm{g})$ and $\mathrm{b}$ is the Langmuir constant $(\mathrm{L} / \mathrm{mg})$. The values of qo and $b$ are calculated from the slope and intercept of the plot of $\frac{C_{e}}{q_{e}}$ versus Ce, respectively. The results are shown in Figures 8 and 9. The maximum adsorption capacity of these adsorbents AMTS and IMTS for adsorption of uranium was obtained 149.3 and 131.4 $\mathrm{mg} / \mathrm{g}$ respectively.

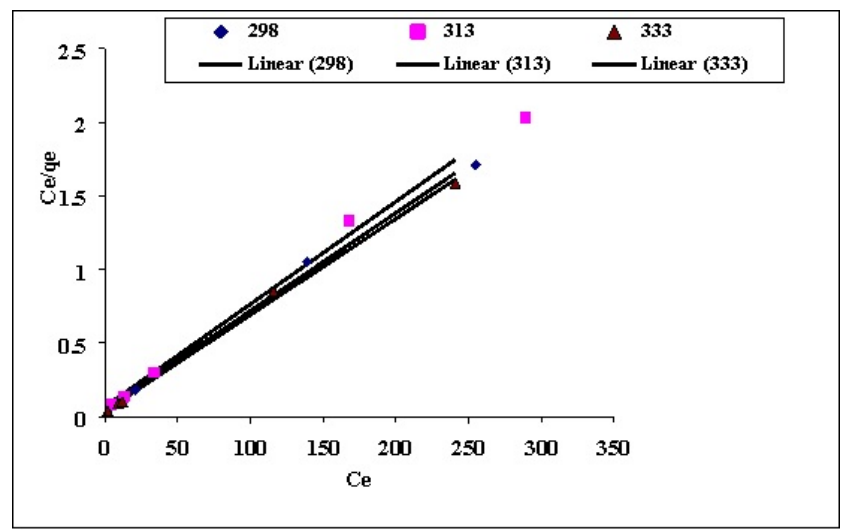

Figure 8: Longmuir Isotherm at different temperatures for AMTS.

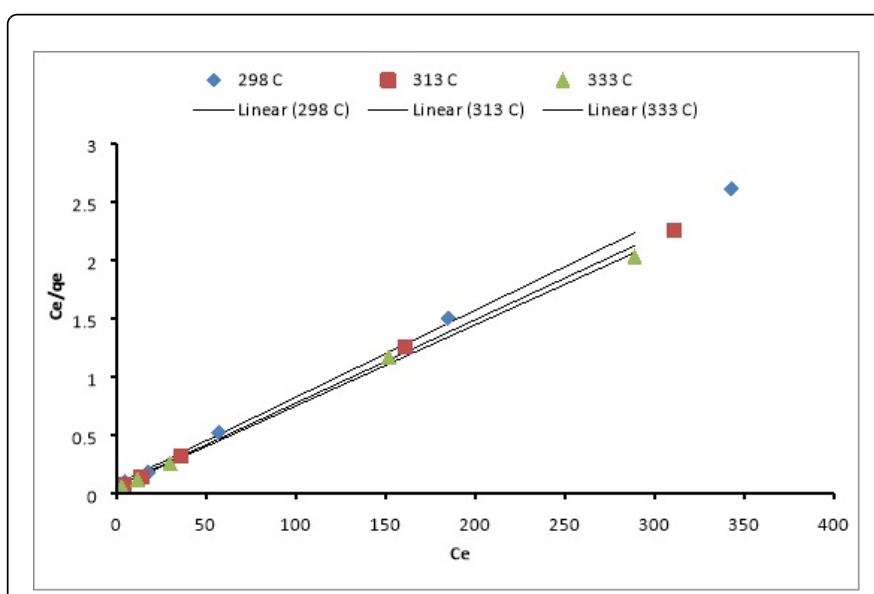

Figure 9: Longmuir Isotherm at different temperatures for IMTS. 
Citation: Gado MA, Abdou AA, Zaki SA (2017) Synthesis of Amino Magnetic Titano-Silicate and Its Role for Uranium Adsorption. Adv Recycling

Page 6 of 9

The linear form of the Freundlich isotherm is shown in Equation 4:

$\log q_{e}=\log K_{f}+\frac{1}{n} \log C_{e}$

Where $\mathrm{K}_{\mathrm{f}}$ is Freundlich constant and $\mathrm{n}$ is the adsorption intensity. The results of the implementation of the experimental data with Freundlich isotherm is shown in Figures 10 and 11. The results of adsorption isotherms of uranium in Table 2 show that the Langmuir isotherm $\left(R^{2} \geq 0.996\right)$ had a good agreement with the experimental data.

Increasing the value of binding constant $\mathrm{Kl}$ with increasing of temperature implies the strong binding between $\mathrm{U}(\mathrm{VI})$ ions and the active sites at elevated temperatures.

\begin{tabular}{|c|c|c|c|c|c|c|c|}
\hline \multirow[t]{2}{*}{ Temperature } & \multicolumn{4}{|c|}{ Langmuir parameters } & \multicolumn{3}{|c|}{ Freundlich parameters } \\
\hline & $q_{\exp }\left(\mathbf{m g g}^{1}\right)$ & $\mathrm{K}_{\mathrm{l}}\left(\mathrm{Lmg}^{-1}\right)$ & $\mathbf{R}^{2}$ & $\mathbf{q}_{\max \text { (AMTS) }}$ & $K_{f}\left(\mathbf{m g ~ g}^{-1}\right)$ & $\mathrm{n}$ & $\mathbf{R}^{2}$ \\
\hline 298 & 142.2 & 1.1291 & 0.9966 & 149.3 & 42.1 & 4.742 & 0.8368 \\
\hline 313 & 149 & 1.3396 & 0.996 & 142.9 & 45.5 & 4.744 & 0.8205 \\
\hline \multirow[t]{2}{*}{333} & 151.8 & 1.7568 & 0.998 & 153.8 & 48.25 & 4.833 & 0.8391 \\
\hline & \multicolumn{7}{|c|}{ IMTS } \\
\hline 298 & 133.33 & 1.2954 & 0.9991 & 131.4 & 45.66 & 4.69 & 0.8143 \\
\hline 313 & 140.85 & 1.4426 & 0.9931 & 137.8 & 49.06 & 4.65 & 0.8193 \\
\hline 333 & 142.86 & 1.7567 & 0.9982 & 142.2 & 55.02 & 4.95 & 0.8022 \\
\hline
\end{tabular}

Table 2: Isotherm parameters for uranium ions removal by AMTS and IMTS.

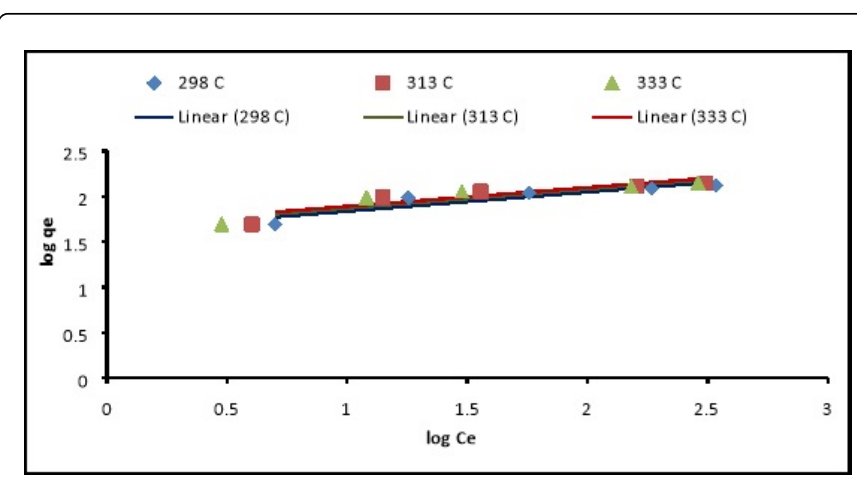

Figure 10: Freundlich Isotherm at different temperatures for AMTS.

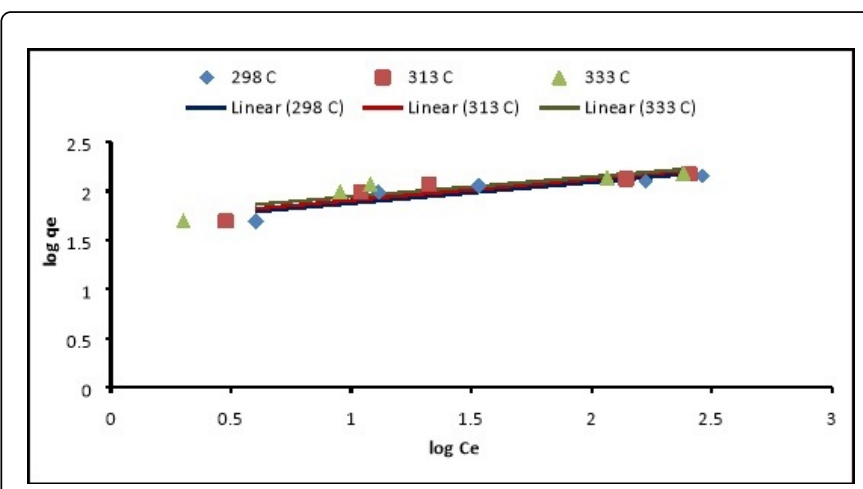

Figure 11: Freundlich Isotherm at different temperatures for IMTS.

\section{Adsorption thermodynamics}

The thermodynamic parameters (average standard enthalpy change $(\Delta \mathrm{H})$, standard entropy change $(\Delta \mathrm{S})$ and standard free energy change $(\Delta \mathrm{G}))$ for the sorption of $\mathrm{U}(\mathrm{VI})$ on AMTS and IMTS composites can be calculated using Van't Hoff equation [35].

$$
\ln K_{L}=\frac{\Delta S^{O}}{R}-\frac{\Delta H^{O}}{R T}
$$

Where $K_{1}$ is the binding constant which is related to the energy of adsorption $\left(\mathrm{Lmg}^{-1}\right), \mathrm{R}$ is the universal gas constant $\left(8.314 \mathrm{Jmol}^{-1} \cdot \mathrm{K}^{-1}\right)$ and $\mathrm{T}$ is the absolute temperature (Kelvin). Plotting $\ln \mathrm{KL}$ against $1 / \mathrm{T}$ as shown in Figure 12 gives a straight line with intercept and slope equal to $\Delta S^{\circ} / \mathrm{R}$ and $-\Delta \mathrm{H}^{\circ} / \mathrm{R}$, respectively. The values of $\Delta \mathrm{S}^{\circ}$ and $\Delta \mathrm{H}^{\circ}$ were calculated and reported in Table 3.

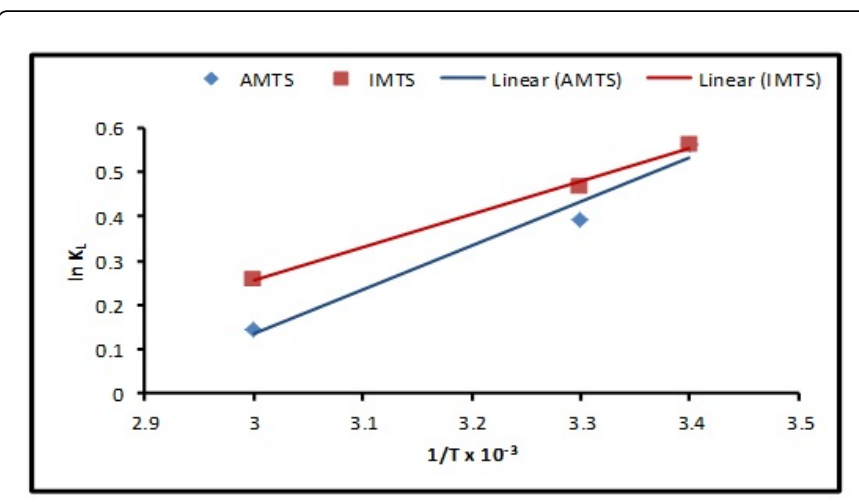

Figure 12: Van't Hoff plot for the U(VI) adsorption on AMTS and IMTS. 


\begin{tabular}{|l|l|l|l|l|l|}
\hline Resin & $\boldsymbol{\Delta H}(\mathbf{k J} / \mathbf{m o l})$ & $\boldsymbol{\Delta S}(\mathrm{KJ} / \mathbf{m o l} . \mathbf{K})$ & \multicolumn{3}{|l|}{$\Delta \mathbf{G}(\mathrm{KJ} / \mathrm{mol})$} \\
\hline \multirow{2}{*}{ AMTS } & 24.74 & \multirow{2}{*}{0.5481} & $298^{\circ} \mathrm{K}$ & $313^{\circ} \mathrm{K}$ & $333^{\circ} \mathrm{K}$ \\
\cline { 4 - 6 } & & & -138.6 & -146.81 & -157.78 \\
\hline IMTS & 39.386 & 0.6486 & -153.8 & -163.6 & -176.6 \\
\hline
\end{tabular}

Table 3: Thermodynamic parameters for U(VI) adsorption onto AMTS and IMTS.

The positive values of $\Delta \mathrm{H}^{\circ}$ indicate that the sorption of $\mathrm{U}(\mathrm{VI})$ on AMTS and IMTS is an endothermic process in nature. The positive values of $\Delta S^{\circ}$ reflect the affinity of AMTS and IMTS toward U(VI) in aqueous solutions and suggest the increased randomness at the solid solution interface during sorption. The negative values of $\Delta \mathrm{G}$ indicate that of the adsorptive performance of U(VI) on the AMTS and IMTS is feasible and spontaneous. The suitability of the resins towards metal ions is through the values of separation factor constant $\left(\mathrm{R}_{\mathrm{L}}\right)$, where $\mathrm{R}_{\mathrm{L}}>1$ (unsuitable); $\mathrm{R}_{\mathrm{L}}=1$ (linear); $0<\mathrm{R}_{\mathrm{L}}<1$ (suitable); $\mathrm{R}_{\mathrm{L}}=0$ (irreversible) [36]. The value of RL could be calculated from Equation 7 :

$$
R_{L}=\frac{1}{1+K_{L} C_{o}}
$$

Where $C_{o}$ is the initial concentration of $\mathrm{U}(\mathrm{VI})$ ions (mg). The values of $\mathrm{R}_{\mathrm{L}}$ for sorption of $\mathrm{U}(\mathrm{VI})$ on AMTS and IMTS composites at different temperature were calculated and found to lie between 0.001 and 0.009 indicating their suitability as adsorbents for $\mathrm{U}(\mathrm{VI})$.

\section{Desorption of composite}

Investigating the process of adsorption and desorption is not only important in optimizing the use of the adsorbent, but also in improving the economic efficiency. Thus, studying the process of adsorption and desorption is necessary.

\begin{tabular}{|c|c|c|c|}
\hline \multirow{2}{*}{ Desorption agent } & \multirow{2}{*}{$\begin{array}{l}\text { Equilibrium adsorption } \\
\text { (\%) }\end{array}$} & \multicolumn{2}{|c|}{ Desorption (\%) } \\
\hline & & AMTS & IMTS \\
\hline $0.01 \mathrm{M} \mathrm{HCl}$ & \multirow{4}{*}{$99.81 \%$ for AMTS } & 52.3 & 54.82 \\
\hline $0.05 \mathrm{M} \mathrm{HCl}$ & & 62.7 & 59.1 \\
\hline $0.1 \mathrm{M} \mathrm{HCl}$ & & 87.6 & 81.1 \\
\hline $0.2 \mathrm{M} \mathrm{HCl}$ & & 97.5 & 93.9 \\
\hline $0.01 \mathrm{M} \mathrm{Na}_{2} \mathrm{CO}_{3}$ & & 44.1 & 37.1 \\
\hline $0.05 \mathrm{M} \mathrm{Na}_{2} \mathrm{CO}_{3}$ & & 46.8 & 38.4 \\
\hline $0.1 \mathrm{M} \mathrm{Na}_{2} \mathrm{CO}_{3}$ & \multirow{3}{*}{$99.21 \%$ for IMTS } & 62.1 & 55.7 \\
\hline $0.2 \mathrm{M} \mathrm{Na}_{2} \mathrm{CO}_{3}$ & & 79.9 & 74.7 \\
\hline $0.5 \mathrm{M} \mathrm{Na}_{2} \mathrm{CO}_{3}$ & & 95.2 & 91.9 \\
\hline
\end{tabular}

Table 4: Effect of eluent agent concentration on the desorption efficiency.

In the present work, the desorption percentage of AMTS and IMTS was carried out with $\mathrm{HCl}$ and $\mathrm{Na}_{2} \mathrm{CO}_{3}$ solutions having different concentrations (0.01-0.2 M) at room temperature. The results demonstrated that the adsorbed $\mathrm{U}(\mathrm{VI})$ could be desorbed from the spent adsorbent using $0.1 \mathrm{M} \mathrm{HCl}$ or $0.5 \mathrm{M} \mathrm{Na}_{2} \mathrm{CO}_{3}$. So that $0.5 \mathrm{M}$ $\mathrm{Na}_{2} \mathrm{CO}_{3}$ is selected to be the desorbing agent due to more economic and didn't make any interaction with composites, (Table 4).

\section{Regeneration-reuse property of composite}

To repeatedly reuse the composites for the recovery of uranium, uranium adsorbed on the resin must be easily eluted with a certain kind of eluents. Also, resin must have the ability to reuse after elution by certain eluent and strong acid was a choice to ensure that strong acid medium, not effect of chemical structure and this is the most properties of resins. Regeneration calculated after 4 cycles for both AMTS and IMTS. The elution was investigated by batch method using $0.5 \mathrm{M} \mathrm{Na} \mathrm{CO}_{3}$ which get show a higher elution of pregnant composites.

\section{Application of the studied resins for granite samples}

Three granite rock samples were collected from Gabal Gattar pluton, located in North Eastern Desert of Egypt. The samples were crushed and ground to -200 mesh size and analyzed by conventional wet chemical techniques for their major oxide compositions as well as by XRF for some trace elements. The chemical analysis of the studied granitic samples is given in Table 5. The granitic samples contain a high concentration of $\mathrm{U}, \mathrm{Th}, \mathrm{Fe}_{2} \mathrm{O}_{3}(\mathrm{t}), \mathrm{Rb}, \mathrm{Y}$, and $\mathrm{Nb}$ and low concentration of $\mathrm{Sr}$ and $\mathrm{Ba}$ compared with similar Egyptian granites. For the work purpose, the uranium content in the granitic samples was selectively leached using nitric acid solution $(2 \mathrm{M})$ for 6 hours at $60^{\circ} \mathrm{C}$. The reacted slurry was filtered and washed with hot water. The obtained filtrate was treated with AMTS and IMTS for the uranium separation. The uptake results of $\mathrm{U}(\mathrm{VI})$ ions (Table 6) showed that both the resins displayed higher removal efficiency towards $\mathrm{U}(\mathrm{VI})$ relative to other metal ions present in the sample solution, while the studied composites showed no affinity towards monovalent cations $(\mathrm{Na}$ + and $\mathrm{K}^{+}$) (Table 7).

\begin{tabular}{|l|l|l|l|l|l|l|l|}
\hline Metal oxides, $\%$ & $\mathrm{SiO}_{2}$ & $\mathrm{Al}_{2} \mathbf{O}_{3}$ & $\mathrm{Fe}_{2} \mathbf{O}_{3}$ & $\mathbf{C a O}$ & $\mathbf{N a}_{2} \mathbf{O}$ & $\mathbf{M g O}$ & $\mathbf{K}_{2} \mathbf{O}$ \\
\hline M1 & 73.5 & 12.8 & 2.5 & 1.3 & 2.6 & 0.5 & 2.4 \\
\hline M2 & 73.2 & 13.8 & 3.6 & 1.4 & 0.7 & 0.6 & 2.5 \\
\hline M3 & 72.6 & 12.7 & 2.5 & 1.3 & 3.9 & 0.5 & 3.4 \\
\hline
\end{tabular}

Table 5: Chemical analysis of major oxides (wt \%), and trace element of the samples collected from Gabal Gattar pluton, located in North Eastern Desert of Egypt.

\begin{tabular}{|l|l|l|l|l|l|l|}
\hline Trace element, $\mathbf{m g} / \mathbf{L}$ & $\mathbf{U}$ & Th & Rare earth & Rb & $\mathbf{Z r}$ & $\mathbf{Y}$ \\
\hline M1 & 3000 & 300 & 270 & 225 & 197 & 126 \\
\hline M2 & 320 & 190 & 270 & $\ldots$ & 400 & 197 \\
\hline M3 & 2700 & 260 & 250 & 437 & 284 & 135 \\
\hline
\end{tabular}

Table 6: Chemical analysis of major oxides (wt \%), and trace element of the samples collected from Gabal Gattar pluton, located in North Eastern Desert of Egypt. 


\begin{tabular}{|l|l|l|l|l|l|l|l|}
\hline \multirow{2}{*}{ Composites } & \multirow{2}{*}{ Metal lon } & \multicolumn{6}{|c|}{ Removal Efficiency } \\
\cline { 3 - 8 } & & \multicolumn{2}{|c|}{ M1 } & \multicolumn{2}{|c|}{ M2 } & \multicolumn{2}{|c|}{ M3 } \\
\cline { 3 - 8 } & & $\%$ & mg/L & $\%$ & mg/L & $\%$ & mg/L \\
\hline \multirow{4}{*}{ AMTS } & U(VI) & 96.1 & 2883 & 99.1 & 317.1 & 96.6 & 2318. \\
& Th(IV) & 60.2 & 174.5 & 68.4 & 130 & 63.4 & 164.8 \\
& RE(III) & 13.1 & 35.4 & 14.7 & 39.7 & 16.1 & 40.25 \\
\hline \multirow{4}{*}{ IMTS } & & & & & & & \\
& U(VI) & 91.8 & 2754 & 93.5 & 299.2 & 93.9 & 2253. \\
& Th(IV) & 54.2 & 157.2 & 62.8 & 119.3 & 59.7 & 155.2 \\
& RE(III) & 11.3 & 30.5 & 12.1 & 32.7 & 10.6 & 26.5 \\
\hline
\end{tabular}

Table 7: Removal efficiency of U(VI) ions compared to other metal ions from granite leach liquors using AMTS and IMTS.

\section{Conclusion}

The two composites AMTS and IMTS were successfully prepared, characterized and examined for uranium adsorption from nitric acid solutions. The Impregnation method was found to be very suitable and low-cost effective method for modification of tirano-silicate. The uptake capacity of amino tirano-silicate prepared with impregnation method was so close to the prepared with other method. Which introduce a new method for modification of Titano-silicate. The adsorption properties Including maximum adsorption capacity, kinetics, and thermodynamics controlling the adsorption process were well-examined using batch method. The adsorption of uranium ions onto AMTS and IMTS is $\mathrm{pH}$ dependent with maximum adsorption at pH 5 and reaching the equilibrium after 45 minutes. The experimental maximum adsorption capacities of AMTS is found to be 142.2, 149 and 151.8 at 298,313 and $343^{\circ} \mathrm{K}$ respectively while the maximum adsorption capacities of IMTS is $133.33,140.85,142.86$ at 298, 313 and $343^{\circ} \mathrm{K}$ respectively, which indicates that the temperature has a positive effect on uranium adsorption. And also indicate high adsorption efficiency of the both composites

\section{References}

1. Harrison WT, Gier TE, Stucky GD (1995) Single-crystal structure of Cs3HTi4O4 $(\mathrm{SiO} 4) 34 \mathrm{H} 2 \mathrm{O}$, a titanosilicate pharmacosiderite analog. Zeolites 15: 408-412.

2. Kuznicki SM, Bell VA, Nair S, Hillhouse HW, Jacubinas RM, et al. (2001) A titanosilicate molecular sieve with adjustable pores for size-selective adsorption of molecules. Nature 16: 720-724.

3. Al Attar L, Dyer A (2001) Sorption of uranium onto titanosilicate materials. J Radioanaly Nuclear Chem 17: 121-128.

4. Da,browski A, Hubicki Z, Podkościelny P, Robens E (2004) Selective removal of the heavy metal ions from waters and industrial wastewaters by ion-exchange method. Chemos 56: 91-106.

5. Kaygun AK, Akyil S (2007) Study of the behaviour of thorium adsorption on PAN/zeolite composite adsorbent. J Hazardous Mat 147: 357-362.

6. Chmielewski AG, Haji-Saeid M (2004) Radiation technologies: past, present and future. Radia Phys Chem 71: 17-21.

7. IAEA (2006) Improvements of Radioactive Waste Management at WWER Nuclear Power Plants. TECDOC 1492: 1-95.

8. Fesenko S, Jacob P, Ulanovsky A, Chupov A, Bogdevich I, et al. (2013) Justification of remediation strategies in the long term after the Chernobyl accident. J Environ Radioactiv 119: 39-47.

9. Kuznicki SM (1990) U.S. Patent 4938 939, 1990.
10. Dąbrowski A (2001) Adsorption from theory to practice. Adv Colloid Interf Sci 93: 135-224.

11. Clearfield A (2000) Inorganic ion exchangers, past, present, and future. Sol Extrac Ion Exchan 18: 655-678.

12. Al-Attar L, Dyer A, Paajanen A, Harjula R (2003) Purification of nuclear wastes by novel inorganic ion exchangers. J Mat Chem 13: 2969-2974.

13. Al Attar L, Dyer A (2001) Sorption of uranium onto titanosilicate materials. J Radioanalyt Nuc Chem 247: 121-128.

14. Al-Attar L, Dyer A, Harjula R (2003) Uptake of radionuclides on microporous and layered ion exchange materials. J Mat Chem 13: 2963-2968.

15. Al-Attar L, Dyer A, Blackburn R (2000) Uptake of uranium on ETS-10 microporous titanosilicate. J Radioanalyt Nuc Chem 246: 451-455.

16. Marczinco Z (1986) Spectrophotometric Determination of Elements. John Wiley and Sons Inc., New York, USA.

17. Donia AM, Atia AA, Moussa EM, El-Sherif AM, El-Magied MO (2009) Removal of uranium (VI) from aqueous solutions using glycidyl methacrylate chelating resins. Hydrometall 95: 183-189.

18. De Raffele G, Aloise A, De Luca P, Vuono D, Tagarelli A (2016) Kinetic and thermodynamic effects during the adsorption of heavy metals on ETS-4 and ETS-10 microporous materials. J Porous Mat 23: 389-400.

19. Milani SA, Karimi M (2017) Isotherm, kinetic and thermodynamic studies for Th (IV) sorption by amino group-functionalized titanosilicate from aqueous solutions. Korean J Chem Eng 34: 1159-1169.

20. Ma JG, Liu YC, Xu CS, Liu YX, Shao CL, et al. (2005) Preparation and characterization of $\mathrm{ZnO}$ particles embedded in $\mathrm{Si} \mathrm{O} 2$ matrix by reactive magnetron sputtering. J App Phy 97: 103509.

21. Bell RJ, Bird NF, Dean P (1986) The vibrational spectra of vitreous silica, germania and beryllium fluoride. J Phys C: Solid State Phys 1: 299.

22. Kusabiraki K (1987) Infrared and Raman spectra of vitreous silica and sodium silicates containing titanium. J Non-Crystall Solids 95: 411-417.

23. Scarano D, Zecchina A, Bordiga S, Geobaldo F, Spoto G, et al. (1993) Fourier-transform infrared and Raman spectra of pure and Al-, B-, Tiand Fe-substituted silicalites: stretching-mode region. J Chem Soc 89: 4123-4130.

24. Anbia M, Lashgari M (2009) Synthesis of amino-modified ordered mesoporous silica as a new nano sorbent for the removal of chlorophenols from aqueous media. Chem Engineer J 150: 555-560.

25. Han R, Zou W, Wang Y, Zhu L (2007) Removal of uranium (VI) from aqueous solutions by manganese oxide coated zeolite: Discussion of adsorption isotherms and $\mathrm{pH}$ effect. J Environ Radioact 93: 127-143.

26. Froideval A, Del Nero M, Barillon R, Hommet J, Mignot G (2003) pH dependence of uranyl retention in a quartz/solution system: an XPS study. J Colloid Interf Sci 266: 221-235.

27. Hennig C, Reich T, Dähn R, Scheidegger AM (2002) Structure of uranium sorption complexes at montmorillonite edge sites. Radiochimica Acta 90: 653-657.

28. Denizli A, Say R, Garipcan B, Patır S (2004) Methacryloylamidoglutamic acid functionalized poly (2-hydroxyethyl methacrylate) beads for UO22+ removal. Reactive Func Poly 58: 123-130.

29. Pekel N, Şahiner N, Akkaş P, Güven O (2000) Uranyl ion adsorptivity of $\mathrm{N}$-vinyl 2-pyrrolidone/acrylonitrile copolymeric hydrogels containing amidoxime groups. Polymer Bull 44: 593-600.

30. Zhang A, Asakura T, Uchiyama G (2003) The adsorption mechanism of uranium (VI) from seawater on a macroporous fibrous polymeric adsorbent containing amidoxime chelating functional group. Reactive Func Polym 57: 67-76.

31. Manju GN, Raji C, Anirudhan TS (1998) Evaluation of coconut husk carbon for the removal of arsenic from water. Water Res 32: 3062-3070.

32. Ho YS, McKay G (1999) Pseudo-second order model for sorption processes. Process Biochem 34: 451-465.

33. Dong W, Brooks SC (2006) Determination of the formation constants of ternary complexes of uranyl and carbonate with alkaline earth metals $(\mathrm{Mg} 2+, \mathrm{Ca} 2+, \mathrm{Sr} 2+$, and $\mathrm{Ba} 2+)$ using anion exchange method. Environ Sci Technol 40: 4689-4695. 
Citation: Gado MA, Abdou AA, Zaki SA (2017) Synthesis of Amino Magnetic Titano-Silicate and Its Role for Uranium Adsorption. Adv Recycling Waste Manag 2: 147. doi:10.4172/2475-7675.1000147

Page 9 of 9

34. Xiong C, Xiaozheng L, Caiping YA (2008) Effect of $\mathrm{pH}$ on sorption for RE (III) and sorption behaviors of Sm (III) by D152 resin. J Rare Earths 26 851-856.

35. Marczenko Z (1986) Separation and spectrophotometric determination of elements. John Wiley and Sons, New York, NY.
36. Hall KR, Eagleton LC, Acrivos A, Vermeulen T (1966) Pore-and soliddiffusion kinetics in fixed-bed adsorption under constant-pattern conditions. Indus Engineer Chem Fundam 5: 212-223. 